\section{Perinatal and childhood risk factors for later criminality and violence in schizophrenia}

\author{
Longitudinal, population-based study \\ MARY CANNON, MATTI O. HUTTUNEN, ANTTI J. TANSKANEN,
LOUISE ARSENEAULT, PETER B. JONES and ROBIN M. MURRAY
}

Background Individuals with schizophrenia appear to be at increased risk for violent and criminal behaviour. Obstetric complications, neuromotor problems and intellectual deficits have variously been reported as increasing the risk for criminality in the general population.

\begin{abstract}
Aims To investigate whether such risk factors are associated with criminal behaviour in an epidemiological cohort of patients with schizophrenia.
\end{abstract}

\begin{abstract}
Method We identified from health care registers all individuals with schizophrenia born in Helsinki between 1951 and 1960, and used the national criminal register to identify those with a criminal record by 1995. Childhood information was obtained from archived birth and school records.
\end{abstract}

\section{Results Poor educational attainment, poor grades for attention at school, higher birth weight and larger head circumference were significantly associated with the risk of criminal offending in adulthood in this sample of patients with schizophrenia. An association between labour/delivery complications and later violent offending among male patients was of borderline significance.}

Conclusions Our hypotheses that birth complications and childhood neuromotor problems would increase the risk of criminal offending in schizophrenia were not upheld.

Declaration of interest None. Funding detailed in Acknowledgements.
Research into the neurobiology of violent behaviour in the general population has begun to focus on early environmental events (Kandel \& Mednick, 1991; Buka \& Earls, 1993; Moffitt, 1993; Volavka, 1995). An association between minor physical anomalies (thought to index foetal maldevelopment) and later aggression and delinquency has long been noted (Waldrop et al, 1978; Arseneault et al, 2000). More recently, a series of investigations from a large Danish birth cohort have demonstrated that perinatal (mainly delivery) complications interact with adverse early environments to increase the risk of violent behaviour among males (Raine et al, 1994, $1996,1997)$ - the so-called 'biosocial interaction' theory of crime causation (Brennan et al, 1997). Investigators have, to a greater or lesser extent, replicated these findings in other samples (Brennan et al, 1997; Tibbetts \& Piquero, 1999; Hodgins et al, 2001; Arseneault et al, 2002). Childhood neurological problems and intellectual deficiency also appear to increase the propensity for later violence (Denno, 1990; Hodgins, 1992). As a body of evidence, these studies suggest that early developmental factors are involved in the predisposition to later violence and criminal offending in the general population.

\section{Background}

The association between schizophrenia and violence has received much public attention in recent years. It has now been demonstrated consistently that male patients with a diagnosis of schizophrenia are between four and seven times more likely to commit violent offences than the general population (for a review, see Walsh et al, 2002, this issue). Because patients with schizophrenia are known to have more birth complications and neurodevelopmental and intellectual impairments than controls (Cannon \& Jones, 1996), such factors may be particularly prevalent in the subgroup of patients who have a propensity to violence. High rates of neurological problems, particularly poor motor coordination, poor visuo-spatial function and low IQ, have been found among inpatients with schizophrenia who have a history of violence (Krakowski et al, 1989), supporting the notion of neurodevelopmental impairment.

In this study we examined the relationship between birth complications, school functioning and later criminal behaviour in a cohort of Finnish patients with schizophrenia using prospectively collected data. We hypothesised that, among individuals with schizophrenia, offenders would be more likely than non-offenders to have: (a) a history of birth complications; (b) poorer motor coordination skills; and (c) lower educational attainment.

\section{METHOD}

\section{Subjects}

We identified all individuals with a diagnosis of schizophrenia who were born in Helsinki between 1951 and 1960, by linkage between three national health care registers: the Finnish Hospital Discharge Register (FHDR), the Free Medicine Register and the Pension Register. The FHDR covers all public and private hospitals in Finland and the discharge diagnoses for each admission are made by the attending physician. The Free Medicine Register and the Pension Register give primary diagnoses for individuals receiving state-subsidised out-patient medication and disability pensions, respectively. Since 1971, all residents of Finland have been assigned a unique personal identification number and this was used to link the register data. Information from these registers was available for the period 1 January 1969 through to 31 December 1991. Before 1987, the ICD-8 diagnostic system was used (World Health Organization, 1969), after which diagnoses were coded according to ICD-9 (World Health Organization, 1987).

\section{Criminal outcome information}

Data on criminal convictions to the end of 1995 were obtained from the Finnish Central Criminal Register, maintained by the Ministry of Justice. A person gets a criminal record when he/she is sentenced with one of the following: imprisonment, fine, community service, youth crime or 
diminished responsibility due to a mental disorder. Records are deleted from the register after different time periods, depending on the severity of the penalty. Records are deleted after 5 years following a suspended sentence of imprisonment or youth crime. Records are deleted after 10 years for sentences of a maximum of 2 years of imprisonment or community service. Records are deleted after 20 years for sentences of more than 2 years of imprisonment or diminished responsibility due to a mental disorder. Crimes with sentences of over 5 years in prison stay on the register and are only deleted after the person dies or reaches 90 years of age. (Information on the Finnish Criminal Register can be found on the Finnishlanguage site http://www.om.fi/148.htm). As in previous studies (Kandel \& Mednick, 1991; Raine et al, 1994, 1996, 1997), the category of violent crimes was taken to include homicides, assault, robbery, arson, illegal possession of a weapon, sexual crime and violation of domestic peace. All other crimes, including theft, blackmail, fraud and driving offences, were defined as nonviolent.

\section{Obstetric information}

There are three large maternity units in Helsinki that have been established since the 1940s: Naistenklinikka 1 and 2, the maternity departments of the Central University Hospital of Helsinki, and Kätilöopisto, a training hospital for midwives. Detailed birth records have been completed by the midwives using similar standardised forms for all women who have given birth in these units. These birth records are stored in the archives of the Helsinki University Central Hospital and the Helsinki City Archives. The records cover the time from admission to the maternity unit until discharge: the first section of the birth record gives demographic information about the mother and a summary of any complications during the pregnancy; the second section describes the examination of the mother by the midwife on admission; the third section details the course of the delivery; and the last section describes the condition of the infant at birth, including measurements of length, head circumference and birth weight and the infant's neonatal progress.

Birth record data were entered onto a specially designed computer database, following the standardised format of the records. Three categories of obstetric complications (yes/no coding) were defined for this study: pregnancy complications, labour/delivery complications and neonatal complications. A positive score on the pregnancy complication variable was awarded if the subject had experienced one or more of the following: preeclampsia, eclampsia, diabetes, bleeding, fever, rhesus incompatibility, anaemia. A positive score for labour/delivery complications was awarded if the subject had experienced one or more of the following: breech or foot presentation, forceps delivery, cephalo- pelvic disproportion, Caesarean section, uterine exhaustion, risk of asphyxia, abnormalities of foetal heart rate or rhythm, cord around neck or body, meconium-stained amniotic fluid, cyanosis, resuscitation or incubator required after delivery. A positive score for neonatal complications indicated one or more of the following: convulsions, intraventricular haemorrhage, transfer to special care baby unit, abnormal neurological signs. Other obstetric information such as birth weight, length at birth and head circumference were also extracted from the birth records and were analysed as continuous variables.

\section{School record cards}

During the period of this study, more than 95\% of children in Finland attended the state elementary school (kansakoulu) system from the age of 7 years (Cannon et al, 1999). Children with learning disabilities $(1.3-1.9 \%)$ or who suffered from emotional or conduct disorder $(0.3-0.8 \%)$ were catered for within the state system in special classes (Somerkivi, 1977). Children attended the school that was closest to their home. All children in the state system studied the same subjects for the first 4 years of schooling. At the end of Grade 4, when children were aged 11 years, each child was given a ranking score (sijaluku) based on the results of their summer examinations. This score helped to determine whether the child went on to high school (oppikoulu), which gave a more academic education, or remained at the elementary school for a further 4 years. This paper examines only the results from the 4 years when all children studied a common programme. The 'core curriculum' subjects were mathematics, religion, reading, writing, handcrafts, physical education and music. We recorded the results of the summer examinations. Marks given for each subject ranged from 4 (fail) to 10 (excellent). All pupils were given marks for conduct and attentiveness each year, and the number of hours of absence without leave was recorded. Most children scored ' 10 ' for conduct but a mark was deducted for transgressing school rules.

\section{Social class information}

Socio-economic group was defined on the basis of paternal occupation recorded on the birth records. Four socio-economic groups were identified on the basis of the City of Helsinki Social Group Classification (Central Statistics Office, 1971), consisting of: (a) professional, managers and higher administrative and clerical staff; (b) lower clerical employees; (c) skilled workers; and (d) unskilled workers. For the purposes of the analysis, these categories were collapsed into two groups: professional/ clerical and skilled/unskilled workers.

\section{Statistical analysis}

Two sets of analyses were carried out: the first set used any criminal record as the outcome, and the second used violent crimes only as the outcome. Obstetric complications were grouped into three categories, as defined earlier: pregnancy, labour/delivery and neonatal complications. Odds ratios with $95 \%$ confidence intervals were obtained for each category of obstetric complications using logistic regression. All models were adjusted for gender. Interaction terms with social class were created for each category and added to the model. Continuous obstetric variables were analysed using one-way analysis of variance, including gender as a covariate. School results were analysed using logistic regression, with robust standard errors adjusted for clustering within subject. All school subjects were entered together into the regression model, with dummy variables for each year of schooling. All analyses were repeated using males only to facilitate comparisons with previous research and to test specific hypotheses relating to males. Logistic regression was used to examine progression to high school, controlling for gender and social class. One-way analysis of variance was used to compare mean rank in class at age 11 years, controlling for social class and stratified by gender. Statistical analyses were carried out using STATA version 6.0 (StataCorp, 1999). The power of this study was sufficient to detect an odds ratio of about 2 
for the relationship between birth complications and later criminality, which is the effect size usually found in general population cohorts (Raine et al, 1994, 1997).

\section{RESULTS}

From a total birth cohort of 97600 individuals born in Helsinki between 1951 and 1960 we identified 928 individuals from the registers $(1.05 \%)$ who had ever been given an ICD-8 or -9 ' 295 ' diagnosis: this included individuals with schizophrenia, schizoaffective disorder or schizophreniform disorder. Birth records were traced for 601 cases $(65.7 \%$ of the total schizophrenia group) and school records in addition were located for 400 cases ( $43 \%$ of the total schizophrenia group).

Of our total cohort of individuals with schizophrenia, $9.4 \%$ (13.4\% of the males and $4 \%$ of females) had a criminal record by 1995 , including $4.3 \%$ convicted of violent crimes. There was a significant excess of males among the offenders $\left(80.3 \% \quad v . \quad 57.2 \% ; \quad \chi^{2}=12.2, \quad\right.$ d.f. $=1$; $P<0.001)$ but no significant difference in the social class distribution. There was no difference between the offenders and the non-offenders on age at first admission with schizophrenia (26.2 v. 25.1 years; $t=-1.5, P=0.14)$. The proportion of cases with criminal records was not significantly different among those cases for whom birth or school records could be found and those for whom they could not be found.

\section{Obstetric complications}

There was no significant relationship between pregnancy or neonatal complications and later criminality or violence (Table 1 ). We tested the 'biosocial interaction' hypothesis by including interaction terms between categories of obstetric complications and social class in the models, but these were not significant. Mean birth weight and head circumference were higher among offenders than among non-offenders (Table 2). There was a tendency for length at birth to be increased among the offenders, but this was not significant. The findings for head circumference but not birth weight remained significant when males were examined separately. A post hoc subgroup analysis, based on the results from the Raine et al (1994, 1996, 1997) series of studies, found a modest association between labour/delivery complications and later conviction for a violent offence among males only, but this finding just missed statistical significance (Table 1). There was no significant change in the odds ratio (OR) for this relationship when we adjusted for birth weight $(\mathrm{OR}=2.05$; $95 \%$ CI $0.95-4.4 ; P=0.067)$, indicating that the association between high birth weight and criminal offending is independent of delivery complications. There were no significant associations between obstetric complications and later criminality or violence when females were examined separately.

\section{School performance}

Offenders were less likely to progress to high school after the first 4 years of elementary schooling than non-offenders (OR (adjusted for gender) $=0.49,95 \% \mathrm{CI}$ $0.25-0.97 ; P=0.042$ ). Male offenders had lower rank in their class at age 11 years than male non-offenders $(0.34(0.05) v$. 0.53 (0.02), $t=3.2$, d.f. $=189 ; P=0.001$ ). When performance in individual subjects was examined, the most consistent differences between offenders and non-offenders

Table I Relationship between obstetric complications and later criminality and violence among patients with schizophrenia for whom birth records were traced

\begin{tabular}{|c|c|c|c|c|c|c|c|c|}
\hline \multirow[t]{3}{*}{ Obstetric exposure (categorical) } & \multicolumn{4}{|c|}{ Total sample $(n=636)$} & \multicolumn{4}{|c|}{ Males only $(n=363)$} \\
\hline & \multicolumn{2}{|c|}{ Any conviction $(n=6 I)$} & \multicolumn{2}{|c|}{ Violent crime $(n=36)$} & \multicolumn{2}{|c|}{ Any conviction $(n=49)$} & \multicolumn{2}{|c|}{ Violent crime $(n=32)$} \\
\hline & $\mathrm{OR}^{2}(95 \% \mathrm{Cl})$ & $P$ & $\mathrm{OR}^{2}(95 \% \mathrm{Cl})$ & $P$ & OR $(95 \% \mathrm{Cl})$ & $P$ & OR $(95 \% \mathrm{Cl})$ & $P$ \\
\hline Pregnancy complications & $0.45(0.2-1.3)$ & 0.1 & $0.42(0.1-1.7)$ & 0.2 & $0.47(0.14-1.6)$ & 0.2 & $0.49(0.11-2.17)$ & 0.3 \\
\hline Labour/delivery complications & $\mathrm{I} .03(0.6-1.7)$ & 0.9 & $1.6(0.8-3.2)$ & 0.2 & $1.3(0.7-2.4)$ & 0.4 & $2.0(0.96-4.4)$ & 0.06 \\
\hline Neonatal complications & $1.08(0.4-2.8)$ & 0.8 & I.I (0.3-3.7) & 0.9 & $0.98(0.3-2.9)$ & 0.9 & $1.16(0.32-4.1)$ & 0.8 \\
\hline
\end{tabular}

I. The reference groups for these analyses are: individuals with schizophrenia who do not have a criminal record and individuals with schizophrenia who do not have a criminal record for violent crime, respectively.

2. Adjusted for gender.

Table 2 Obstetric complications (continuous variables) and later criminality and violence among patients with schizophrenia for whom birth records are available'

\begin{tabular}{|c|c|c|c|c|c|c|c|c|c|c|}
\hline \multirow{3}{*}{$\begin{array}{l}\text { Obstetric exposure } \\
\text { (continuous measures) }\end{array}$} & \multirow{3}{*}{$\begin{array}{l}\begin{array}{c}\text { Criminal record } \\
(n=6 \mathrm{I})\end{array} \\
\frac{\text { Mean (s.e.) }}{}\end{array}$} & \multirow{3}{*}{$\begin{array}{c}\text { No criminal } \\
\text { record }(n=575) \\
\text { Mean (s.e.) }\end{array}$} & \multicolumn{4}{|c|}{ Total sample $(n=636)$} & \multicolumn{4}{|c|}{ Males only $(n=363)$} \\
\hline & & & \multicolumn{2}{|c|}{$\begin{array}{l}\text { Any conviction } \\
\qquad(n=6 \mathrm{I})\end{array}$} & \multicolumn{2}{|c|}{$\begin{array}{l}\text { Violent crime only } \\
\qquad(n=36)\end{array}$} & \multicolumn{2}{|c|}{$\begin{array}{l}\text { Any conviction } \\
\qquad(n=49)\end{array}$} & \multicolumn{2}{|c|}{$\begin{array}{l}\text { Violent crime only } \\
\qquad(n=32)\end{array}$} \\
\hline & & & $F^{2}$ (d.f.) & $P$ & $F^{2}$ (d.f.) & $P$ & $F($ d.f. $)$ & $P$ & $F($ d.f. $)$ & $P$ \\
\hline Birth weight & 3602.3 (58.9) & $3436.5(22.1)$ & $3.9(2,605)$ & 0.05 & $0.86(2,605)$ & 0.35 & $1.9(1,360)$ & 0.2 & $0.11(1,360)$ & 0.7 \\
\hline Length & $50.8(0.2 \mathrm{I})$ & $50.2(0.08)$ & $3.1(2,604)$ & 0.08 & $1.6(2,604)$ & 0.21 & $2.5(1,359)$ & 0.12 & $0.4(1,359)$ & 0.5 \\
\hline Head circumference & $35.3(0.16)$ & $34.9(0.06)$ & $4.8(2,488)$ & 0.03 & $3.04(2,488)$ & 0.18 & $4.6(I, 29 I)$ & 0.03 & $0.9(1,291)$ & 0.3 \\
\hline
\end{tabular}

I. The reference groups for these analyses are: individuals with schizophrenia who do not have a criminal record and individuals with schizophrenia who do not have a criminal record for violent crime, respectively.

2. Adjusted for gender. 
Table 3 Relationship between school performance and later criminality and violence among patients with schizophrenia for whom school records were available'

\begin{tabular}{|c|c|c|c|c|c|c|c|c|}
\hline \multirow[t]{3}{*}{ School performance } & \multicolumn{4}{|c|}{ Total sample $(n=400)$} & \multicolumn{4}{|c|}{ Males only $(n=\mid 91)$} \\
\hline & \multicolumn{2}{|c|}{$\begin{array}{l}\text { Any conviction } \\
\qquad(n=44)\end{array}$} & \multicolumn{2}{|c|}{$\begin{array}{l}\text { Violent crime } \\
\qquad(n=26)\end{array}$} & \multicolumn{2}{|c|}{$\begin{array}{l}\text { Any conviction } \\
\qquad(n=36)\end{array}$} & \multicolumn{2}{|c|}{$\begin{array}{l}\text { Violent crime } \\
\qquad(n=23)\end{array}$} \\
\hline & $\mathrm{OR}^{2,3}(95 \% \mathrm{Cl})$ & $P^{2}$ & $\mathrm{OR}^{2,3}(95 \% \mathrm{Cl})$ & $P^{2}$ & $\mathrm{OR}^{2,3}(95 \% \mathrm{Cl})$ & $P$ & $\mathrm{OR}^{2,3}(95 \% \mathrm{Cl})$ & $P$ \\
\hline Attentiveness & $0.62(0.5-0.8)$ & 0.001 & $0.7(0.5-0.9)$ & 0.03 & $0.6(0.5-0.8)$ & 0.002 & $0.7(0.5-1.0)$ & 0.05 \\
\hline Reading & $1.3(0.9-1.8)$ & 0.13 & $0.9(0.6-1.4)$ & 0.8 & $1.4(0.96-1.9)$ & 0.08 & I.I (0.7-1.6) & 0.7 \\
\hline Writing & $0.8(0.6-1.1)$ & 0.16 & $0.8(0.6-1.2)$ & 0.4 & $0.7(0.5-1.04)$ & 0.09 & $0.8(0.6-1.3)$ & 0.4 \\
\hline Mathematics & $0.9(0.7-1.2)$ & 0.7 & $1.0(0.8-1.4)$ & 0.7 & $0.9 \quad(0.7-1.2)$ & 0.5 & $1.0(0.8-1.4)$ & 0.8 \\
\hline Religion & $0.9(0.6-1.3)$ & 0.6 & $0.8(0.5-1.3)$ & 0.4 & $0.9(0.6-1.4)$ & 0.7 & $0.8(0.5-1.3)$ & 0.4 \\
\hline Music & $1.0(0.8-1.3)$ & 0.8 & I.I (0.8-I.5) & 0.4 & 0.9 (0.7-1.3) & 0.9 & $0.9(0.7-1.3)$ & 0.9 \\
\hline Handcrafts & $1.4(1.1-1.7)$ & 0.004 & $1.4(I . I-1.7)$ & 0.01 & $1.4 \quad(I .1-1.8)$ & 0.01 & $1.4(1.0-1.8)$ & 0.03 \\
\hline Sport & I.I (0.8-1.6) & 0.5 & I.I (0.7-I.7) & 0.6 & $0.9(0.6-1.3)$ & 0.6 & $0.9(0.6-1.4)$ & 0.7 \\
\hline Absences & $1.0(0.9-1.01)$ & 0.6 & $1.0(0.9-1.1)$ & 0.2 & $0.9(0.9-1.0 \mathrm{I})$ & 0.9 & $1.0(0.9-1.01)$ & 0.4 \\
\hline
\end{tabular}

I. The reference groups for these analyses are: individuals with schizophrenia who do not have a criminal record and individuals with schizophrenia who do not have a criminal record for violent crime, respectively.

2. Adjusted for gender.

3. The odds ratios can be interpreted as risk of criminality or violent crime per unit increase in grade for each item of school performance.

were on grades for attentiveness and handcrafts (Table 3). The offenders had significantly lower teacher ratings for attentiveness than non-offenders, and the odds of later having a criminal record decreased by about $30 \%$ for each increase in the grade for attentiveness. These differences persisted when violent crimes only were examined separately and when male subjects were analysed separately. There was no significant change in the odds ratio for the relationship between attentional problems and later offending $(\mathrm{OR}=0.67,95 \%$ CI $0.5-0.9 ; P=0.01$ ) when delivery complications, birth weight, length and head circumference were entered into the regression model, indicating that the lower score for attentiveness among the offenders is not due to obstetric factors. In contrast, the offenders scored higher than the nonoffenders on handcrafts and the odds of later having a criminal record increased by $40 \%$ for each unit increase in the grade for handcrafts. There were no significant differences between the groups for scores in academic subjects, religion or music or number of days absent from school without permission. There was no significant difference between the offenders and the nonoffenders for teacher ratings of conduct. None of the offenders and less than $1 \%$ of the non-offenders had ever been deducted marks for conduct (i.e. score of $<10$ ).

\section{DISCUSSION}

\section{Methodological issues}

The advantages of this study are the availability of prospectively recorded childhood information, independently ascertained criminal outcome data and a large population-based sample of patients with schizophrenia, including both male and female subjects. There are also some limitations. First, we have relied on register diagnoses of schizophrenia but these registers have been shown to have excellent specificity for schizophrenia and detect more than $90 \%$ of psychotic patients (Isohanni et al, 1997). Second, the criminal register is cleared of records after varying periods of time following different sentences, which means that some cases will have been misclassified as having no criminal record when in fact they may have had one in the past. This misclassification would act to reduce our chances of finding significant effects rather than leading to false-positive findings. In that sense, our study could be conceptualised as examining risk factors for 'serious' crime rather than offending in general. Third, although those given a sentence of diminished responsibility due to mental disorder are included in the criminal register, we do not know what proportion of offenders known to have a history of psychotic illness might be 'diverted' to in-patient treatment without appearing in court. Records of court convictions may, therefore, underestimate actual offending behaviour in our sample or may represent selectively a subgroup of offenders with mental illness. Fourth, there is a considerable amount of missing data for childhood records, but the proportion of individuals with a criminal record was not significantly different among those cases for whom birth or school records were traced or not traced, indicating that the 'missingness' of childhood records was independent of later criminal outcome. Finally, the lack of criminal and childhood data on a normal control group means that we cannot test whether the associations found in this study are relevant to criminal offending in general or are specific to schizophrenia. However, we have quoted extensively from research by other investigators who have found such early risk factors for criminality in general population birth cohorts.

\section{Rates of criminal offending}

In this cohort of individuals with schizophrenia, over $13 \%$ of males and $4 \%$ of females had a criminal record by 1995 when aged between 35 and 44 years. These rates correspond well with results by Brennan et al (2000), who found that $11.3 \%$ of males with schizophrenia and 
$2.8 \%$ of females with schizophrenia from a Danish birth cohort ranging between 44 and 47 years in age had a criminal record by 1991 . Tiihonen et al (1997) found that $20.6 \%$ of male patients with schizophrenia in the North Finland 1966 birth cohort had a criminal record by 25 years of age. The lower rate of criminal offending in our sample may be due to the older age of our sample and the fact that some criminal records for less serious offences may have already been deleted from the register.

\section{Birth complications and later offending}

We did not prove our first hypothesis that a history of obstetric complications increased the risk for later criminal conviction in schizophrenia - nor did we find a 'biosocial' interaction between obstetric complications and low social class. However, Finland in the 1950s was a rather egalitarian society, and social class based on occupation did not necessarily correlate with social deprivation or neglect. No direct measure of maternal rejection as used by other researchers (Raine et al, 1994, 1997; Hodgins et al, 2001) was available in this sample.

Previous work (Tibbetts \& Piquero, 1999) has found a relationship between low birth weight and later criminality in the general population. In contrast, we found that, among this sample of individuals with schizophrenia, offenders had significantly higher birth weight and a larger head circumference than nonoffenders. We did not have information on maternal smoking during pregnancy, which has been linked to adult violent crime (Brennan et al, 1999; Räsänen et al, 1999), but if such a link had been present in our sample we would have expected lower birth weights among the offenders. We can speculate that higher birth weight predicts larger physique later in life. Raine et al (1998) found that large body size at age 3 years is related to aggression at age 11 years.

Although the association between labour/delivery complications and an increased risk of violent crime among males was not statistically significant, this subgroup analysis did not have sufficient power to discount such a relationship or to test for a biosocial interaction effect. But, in any case, labour/delivery complications only accounted for about $1 \%$ of the variance in violent offending in our sample and are thus not a major risk factor for violence in schizophrenia.

\section{Motor coordination and later offending}

Contrary to our second hypothesis, we failed to find any association between later offending and childhood neuromotor problems as indexed by school performance in sports and handcrafts. In fact, those cases with a criminal conviction actually performed better at handcrafts in school than cases without a conviction. This negative finding is unexpected, because a previous study on this sample found that poor performance in sports and handcrafts was the most significant predictor of later schizophrenia related to school performance (Cannon et al, 1999).

\section{Educational attainment and later offending}

Individuals with schizophrenia who were later convicted of a criminal offence had a lower rank in their class at age 11 years and were less likely to progress to the academic high school than those without a criminal conviction. This accords with other work showing a history of poor educational attainment and learning difficulties among patients with schizophrenia who have a history of offending (Schanda et al, 1992; Heads \& Taylor, 1997). Offenders had significantly lower ratings for attentiveness than non-offenders throughout their school career. What is the possible mechanism for this effect? Neuropsychological studies of antisocial offenders show attentional problems (Henry \& Moffitt, 1997) and children with attention-deficit hyperactivity disorder have higher rates of delinquency and adult criminal convictions (Farrington et al, 1996). Therefore we may, in fact, be detecting comorbid antisocial personality disorder or childhood attention-deficit hyperactivity disorder. Arguing against this, however, is the fact that none of the offenders had been noted as having major conduct problems at school. It is also possible that poor attentiveness persists into adulthood and this group is merely less good at being criminal (i.e. more easily detected by the police) than the attentive group.

Although two out of three of our initial hypotheses were not upheld, our findings lead to further hypotheses regarding, for instance, the possible links between poor attentiveness or higher birth weight and later offending in schizophrenia. The literature in this area should continue to move beyond what is well-established - that there is a link between crime and schizophrenia - and towards the more interesting question of what mechanism or mechanisms account for this association.

\section{ACKNOWLEDGEMENTS}

This research was supported by a research grant from the Theodore and Vada Stanley Foundation. M.C. was supported by an Advanced Research Training Fellowship from the Wellcome Trust (UK) and L.A. was supported by fellowships from the Social Sciences and Humanities Research Council of Canada and the US National Consortium on Violence Research. We wish to acknowledge the following individuals for their contribution to this project: Professor Jouko Lönnqvist, Tiia Pirkola, Pirjo Käki, Pekka Hahle and the staff of the Helsinki City Archives.

\section{REFERENCES}

Arseneault, L., Tremblay, R. E., Boulerice, B., et a (2000) Minor physical anomalies and family adversity as risk factors for violent delinquency in adolescence. American Journal of Psychiatry, 157, 917-923.

_, _ , , et al (2002) Obstetric complications and adolescent violent behaviours: testing two developmental pathways. Child Development, 73 496-508.

Brennan, P., Mednick, S. \& Raine, A. (1997) Biosocia interactions and violence: a focus on perinatal factors. In Biosocial Bases of Violence (eds A. Raine, P. Brennan, D. Farringdon, et al), pp. 163-174. New York: Plenum Press.

_ , Grekin, E. R. \& Mednick, S. A. (1999) Materna smoking during pregnancy and adult male criminal outcomes. Archives of General Psychiatry, 56, 215-219.

_ , Mednick, S. A. \& Hodgins, S. (2000) Major mental disorders and criminal violence in a Danish birth cohort. Archives of General Psychiatry, 57, 494-500.

Buka, S. \& Earls, F. (1993) Early determinants of delinquency and violence. Health Affairs, 12, 46-64.

Cannon, M. \& Jones, P. (1996) Schizophrenia: neuroepidemiology review series. Journal of Neurology, Neuropsychiatry and Neurosurgery, 61, 604-613.

_ , Jones, P., Huttunen, M. O., et al (1999) School performance in Finnish children and later development of schizophrenia: a population-based longitudinal study. Archives of General Psychiatry, 56, 457-463.

Central Statistics Office (197I) Alphabetical Coding Manual for Social Class Based on Occupations: Population Census 1970. Helsinki: Central Statistics Office.

Denno, D.W. (1990) Biology and Violence: from Birth to Adulthood. New York: Cambridge University Press.

Farrington, D. P., Loeber, R. \& Van Kammen, W. B. (1996) Long term criminal outcomes of hyperactivity impulsivity-attention deficit and conduct disorder in childhood. In Straight and Devious Pathways from Childhood to Adulthood (eds L. Robins \& M. Rutter), pp. 62-81. Cambridge: Cambridge University Press.

Heads, T. \& Taylor, P. J. (1997) Childhood experiences of patients with schizophrenia and a history of violence: 
a special hospital sample. Criminal Behaviour and Mental Health, 7, II7-130.

Henry, B. \& Moffitt, T. E. (1997) Brain-behaviour relations in antisocial individuals: evidence from neuropsychological tests and neuroimaging studies. In Handbook of Antisocial Behaviour (eds D. Stoff, J. Breding \& J. Maser), pp. 280-288. New York: John Wiley \& Sons.

Hodgins, S. (1992) Mental disorder, intellectual deficiency and crime. Archives of General Psychiatry, 49, $476-483$

—, Kratzer, L. \& McNeil, T. (200I) Obstetric complications, parenting and the risk of criminal behaviour. Archives of General Psychiatry, 58, 746-752.

Isohanni, M., Mäkikyrö, T., Moring, J., et al (1997) A comparison of clinical and research DSM-III-R diagnoses of schizophrenia in a Finnish national birth cohort. Social Psychiatry and Psychiatric Epidemiology, 32, 303-308.

Kandel, E. \& Mednick, S. A. (1991) Perinatal complications predict violent offending. Criminology, 29, 519-529.

Krakowski, M. I., Convit, A., Jaeger, J., et al (1989) Neurological impairment in violent schizophrenic inpatients. American Journal of Psychiatry, 146, 849-853.

Moffitt, T. E. (1993) Adolescence-limited and lifecourse persistent antisocial behaviour: a developmental taxonomy. Psychological Reviews, 100, 674-701.

Raine, A., Brennan, P. \& Mednick, S. A. (1994) Birth complications combined with early maternal rejection at age I year predispose to violent crime at age 18 years. Archives of General Psychiatry, 5I, 984-988.

_, _ Mednick, B., et al (1996) High rates of violence, crime, academic problems and behavioural problems in males with both early neuromotor deficits and unstable family environments. Archives of General Psychiatry, 53, 544-549.

_, _ \& Mednick, S. A. (1997) Interactions between birth complications and early maternal rejection in predisposing individuals to adult violence: specificity to serious, early-onset violence. American Journal of Psychiatry, 154, 1265-1271.

\section{—, Reynolds, C., Venables, P., et al (1998)}

Fearlessness, stimulation-seeking and large body size at age 3 years as early predispositions to childhood aggression at age II years. Archives of General Psychiatry, 55, 745-751.

\section{Räsänen, P., Hakko, H., Isohanni, M., et al (1999)}

Maternal smoking during pregnancy and risk of crimina behaviour among adult male offspring in the Northern Finland 1966 birth cohort. American Journal of Psychiatry, I56, 857-862.

Schanda, H., Foldes, P., Topitz, A., et al (1992) Premorbid adjustment of schizophrenic criminal offenders. Acta Psychiatrica Scandinavica, 86, 121-126.

Somerkivi, U. (1977) The History of Helsinki's Elementary Schools. Helsinki: Finnish Literature Press. StataCorp (1999) Intercooled Stata 6.0 for Windows 98/95/NT. College Station, TX: Stata Corporation.

Tibbetts, S. \& Piquero, A. (1999) The influence of gender, low birth weight and disadvantaged

\section{CLINICAL IMPLICATIONS}

- This study indicates that in schizophrenia, as in the general population, some risk factors for later criminal and violent offending can be identified early in life, even before diagnosis.

- The finding that attentional problems in childhood are associated with an increased risk of later criminality may provide clues to the neuropsychological basis of criminal offending in schizophrenia.

- Enquiring about childhood factors can increase the power of risk assessment models for males with a schizophrenic illness.

\section{LIMITATIONS}

- The lack of a normal control group means that we cannot determine whether our findings are relevant to criminal and violent offending in general or are specific to schizophrenia.

- There was a considerable amount of missing childhood data but it was not significantly different beween offenders and non-offenders and was thus independent of criminal outcome.

- This study relies on register diagnoses for schizophrenia rather than standardised patient interviews.

MARY CANNON, MRCPsych, Institute of Psychiatry, London; MATTI O. HUTTUNEN, PhD, ANTTI J. TANSKANEN, BSc, Department of Mental Health and Alcohol Research, National Public Health Institute, Helsinki; LOUISE ARSENEAULT, PhD, Social, Genetic, and Developmental Psychiatry Research Centre, Institute of Psychiatry, London; PETER B. JONES, MRCPsych, University of Cambridge, UK; ROBIN M. MURRAY, MRCPsych, Institute of Psychiatry, London, UK

Correspondence: Mary Cannon, Division of Psychological Medicine, Institute of Psychiatry, De Crespigny Park, Denmark Hill, London SE5 8AF, UK. Tel: 0207848 04I5; fax: 020 770I 9044; e-mail: m.cannon@iop.kcl.ac.uk

(First received 10 September 200I, final revision 25 February 2002, accepted 25 February 2002)

environment in predicting early onset of offending: a test of Moffitt's interactional hypothesis. Criminology, 37, 843-877.

Tiihonen, J., Isohanni, M., Räsänen, P., et al (1997) Specific major mental disorders and criminality: a 26-year prospective study of the 1996 Northern Finland birth cohort. American Journal of Psychiatry. I54, 840-845.

Volavka, J. (1995) Neurobiology of Violence. Washington, DC: American Psychiatric Press

Waldrop, M. F., Bell, R. Q., McLaughlin, B., et al (1978) Newborn minor physical anomalies predict short attention span, peer aggression and impulsivity at age 3 . Science, 199, 563-565.

Walsh, E., Buchanan, A. \& Fahy, T. (2002)

Schizophrenia and violence: examining the evidence. British Journal of Psychiatry, 180, 490-495.

World Health Organization (1969) Internatinal Classification of Diseases, Eighth Revision (ICD-8). Geneva: WHO.

- (1987) International Classification of Diseases, Ninth Revision (ICD-9). Geneva: WHO. 